\title{
Use of Thrombolytics in Pulmonary Thromboembolism with High- Risk Markers or High Thrombus Burden without Hemodynamic Compromise
}

Pro

IGNACIO M. SEROPIAN (iD)

Acute pulmonary thromboembolism (PTE) is the third cause of cardiovascular death worldwide. (1) For hemodynamically unstable patients with no contraindications, the treatment of choice consists of intravenous (IV) systemic thrombolytic agents, Class I recommendation (Level of Evidence B) in the 2016 Guidelines of the Argentine Society of Cardiology (2), the 2016 American guidelines (3), and the most recent 2019 European guidelines. (4) For hemodynamically stable patients, guidelines generally do not recommend systemic thrombolytic therapy due to risk of intracranial bleeding. However, this group of "normotensive" patients is very heterogeneous, including patients with high chance of torpid evolution and death associated with acute right ventricular (RV) failure, which may reach up to $15 \%$ of cases in some series. (5) In this group, subclassification according to risk is of special interest, for which various scores have been developed and validated to consider pre-existing comorbidities, cardiac biomarkers, and the alteration of RV function and geometry. The most validated models are the PESI score, and its simplified version sPESI. (6) However, there are also other markers that exceed scores, such as syncope, transit thrombus, or increased lactic acid, which have also proved to be prognostic factors. (7) In the recently published CONAREC XX registry, $60 \%$ of patients presented intermediate-risk PTE without hemodynamic compromise and $24 \%$ of them were subclassified as intermediate-high risk patients. (8) This subgroup of patients presented a mortality rate $>12 \%$, even higher than the mortality rate for ST-segment elevation acute myocardial infarction in our setting. (9) In turn, when the PESI score was used, mortality rate for the highest-risk group (PESI V) was $32 \%$, i.e. almost 1 out of every 3 patients. (8) Therefore, this subgroup can present a torpid course, generating interest in developing more aggressive treatments than simple anticoagulation.
Undoubtedly, the most important clinical study evaluating the effect of systemic thrombolytic therapy in PTE patients without hemodynamic instability was the PEITHO trial, a double-blind, randomized, multicenter clinical study that included more than 1,000 intermediate/high-risk PTE patients. (10) This group was defined by the evidence of RV dysfunction detected on echocardiography or CT scan and increased cardiac troponin in the absence of hemodynamic compromise. These patients were randomized to receive either systemic thrombolysis with tenecteplase (unavailable in Argentina) or placebo, plus heparin for anticoagulation. In this study, fibrinolytic therapy was associated with a significant decrease in the primary endpoint of hemodynamic deterioration or death at 7 days (tenecteplase $2.6 \%$ vs $5.6 \%$ anticoagulation, OR $0.44,95 \%$ CI $0.23-0.87, \mathrm{p}=0.02$ ), mainly due to reduced progression to shock, with no significant difference in mortality (tenecteplase $1.2 \%$ vs $1.8 \%$ anticoagulation). These positive efficacy outcomes were contrasted by a significant increase in the rate of major bleeding $(11.4 \%$ vs $2.4 \%, \mathrm{p}<0.001)$ and intracranial bleeding ( $2 \%$ vs $0.2 \% ; \mathrm{p}=0.03$ ). By analyzing the PEITHO population in detail, we can see that while it was an "intermediate-high" risk group in the European classification, it included clinically stable patients, with a tendency toward hypertension, no tachycardia, with almost normal respiratory rate, and not requiring oxygen supply in up to $15 \%$ of cases. These parameters that are part of the PESI score -not used in the PEITHO trial- could identify those patients who would have a favorable risk-benefit profile for the use of systemic thrombolytic agents. In this regard, a post-hoc analysis of the PEITHO trial showed that only $9 \%$ of the population presented at least 2 highrisk parameters of the score, and that these patients' outcome was better with thrombolytic therapy than with anticoagulation. (11) In order to select the most 
ideal population for systemic thrombolytic agents, the risk of bleeding should be assessed with useful PTE scores, though none has been specially validated for thrombolytic treatment. (12) Finally, a meta-analysis of 8 randomized clinical trials (including the PEITHO trial) in 1,755 patients without hemodynamic compromise (13) comparing thrombolytic therapy vs. anticoagulant therapy, showed that thrombolysis was associated with significantly lower mortality (OR 0.48 , 95\% CI, 0.25-0.92, $\mathrm{p}=0.03$ ) and increased rate of major bleeding events (OR 3.19, 95\% CI, 2.07-4.92, p < 0.001)

Since systemic thrombolytic therapy is associated with an increased risk of intracranial bleeding, but considering that anticoagulant therapy may not be enough for the highest-risk subgroup, additional therapeutic alternatives to anticoagulation have emerged to prevent hemodynamic deterioration without increasing the risk of bleeding. Percutaneous catheter treatment is one of the most attractive alternatives, in continuous development. $(5,14)$ The modalities of percutaneous treatment of acute PTE include mechanical thrombectomy (disruption or aspiration), and local thrombolytic infusion at the thrombus level. The technique of mechanical thrombectomy has evolved from the historical fragmentation by rotation of catheters -with the potential risk of distal embolization- to more modern techniques of aspiration and extraction of the clot in block. (15) Although device characteristics exceed the purpose of this controversy because thrombolytic agents are not used, they are generally introduced percutaneously through the femoral vein and present a wide variety of diameters. Larger devices allow the removal of large thrombi at the expense of greater aspiration of patient blood; while smaller thrombi limit blood extraction but are unable to aspirate the large thrombi (including the saddle thrombus that straddles the pulmonary artery trunk and is associated with poor prognosis). The extraction method can be manual (syringe) or through a mechanical system connected to a filter.

Despite their diversity, there are no randomized clinical trials assessing catheter-based thromboaspiration, and the strongest evidence comes from some prospective registries without a control group, performed to get the approval from the U.S. Food and Drug Administration. (14) Local thrombolytic infusion via catheter is justified by the fact that there is a preferential blood flow to the perfused areas of the lung, which "distances" the intravenously administered thrombolytic agent from where it should act. (16) This allows to significantly reduce total thrombolytic dose to about a quarter of the systemic dose, lowering the rate of severe bleeding while maintaining its effectiveness. Therefore, it is an alternative to anticoagulation alone in patients with intermediatehigh risk PTE, being safer than the administration of systemic thrombolytic agents.

From a practical viewpoint, the infusion is per- formed through venous puncture (generally femoral, but it can also be jugular or antebrachial vein). The catheter is then advanced to one or both pulmonary branches where there is greater thrombotic load, and infusion of the thrombolytic agent -commonly alteplase- is started at a speed no greater than $1 \mathrm{mg} / \mathrm{h}$, for about 12-20 h. There is no consensus on the treatment dose and duration, and other shorter regimes from 2 to $6 \mathrm{~h}$, with lower doses- have been analyzed. (17) A multicenter, randomized clinical trial called ULTIMA ( $\mathrm{n}=59$ ) studied the effect of ultrasound-assisted local fibrinolytic administration (to improve the drug contact with the clot) for PTE in major branches, in hemodynamically stable patients but with (intermediate-high risk) RV overload. (18) Alteplase was infused at a dose of $21 \mathrm{mg}$ during 15 hours in patients with bilateral PTE. Local thrombolytic therapy significantly reduced $\mathrm{RV}$ overload ratio 24 hours after treatment initiation (primary endpoint), an effect not found with anticoagulation alone. No major bleeding was observed in this study, and minor bleeding rate was low and similar between the two groups $(10 \%$ vs $3 \% ; \mathrm{p}=0.6)$. Prospective registries confirmed the safety and effectiveness of this technique in reducing pulmonary pressures, although no comparative studies with clinical endpoints are available. (14, 19, 20) Furthermore, the role of ultrasound per se is discussed, since a randomized comparative study of local thrombolysis with and without ultrasound showed no difference in patients with proximal deep vein thrombosis, (21) and a prospective registry showed no difference in PTE. (18)

Finally, in order to obtain the best risk-benefit ratio in hemodynamically stable patients, the administration of systemic thrombolytic agents has been studied, but at half the established dose. The Moderate Pulmonary Embolism Treated with Thrombolysis trial (MOPETT) $(\mathrm{n}=121)$ was a randomized, singlecenter study that compared low doses of alteplase (50 $\mathrm{mg}$ ) versus anticoagulation in intermediate-risk PTE patients. (22) This study demonstrated that low doses of systemic thrombolytic agents were associated with reduced pulmonary hypertension at follow-up ( $16 \%$ vs $57 \%, \mathrm{p}<0.001$ ), and a trend to a lower rate of recurrent PTE $(0 \%$ vs $5 \%, \mathrm{p}=0.08)$. No major or minor bleeding was observed in either study group. Although it was an "intermediate-risk" population -defined by imaging and clinical variables-, only $68 \%$ showed increased markers of myocardial stress, and only $21 \%$ presented RV enlargement. The PEITHO-III trial, currently in design phase, will evaluate the efficacy of half-dose thrombolytics in this group of intermediatehigh risk PTE patients with clinical endpoints. (14)

In summary, hemodynamically stable PTE with high risk markers represents a therapeutic challenge given its high possibility of progression to shock. Thrombolytics are a very useful treatment in this group of intermediate-high risk patients, in different modalities of administration and doses. Full systemic 
dosing is not usually recommended for this population due to the results of the PEITHO trial -the largest study in normotensive patients-, although a very selected subgroup of patients with very high risk of progression to shock but who do not yet meet shock criteria (preshock), and who also have very low risk of bleeding, might benefit from this treatment. There are other markers (transit thrombus, syncope, lactic acidosis, absence of initial anticoagulation response) that may influence this treatment choice in certain situations. Furthermore, the administration of local thrombolytics in the pulmonary artery is a very attractive strategy since discharge to the RV is faster than anticoagulation but with a lower risk of bleeding, given that it uses a quarter of the total thrombolytic dose. The result is a treatment with an excellent risk-benefit profile. As a counterpart, it is an invasive procedure that increases costs, and requires trained professionals and patient collaboration during the infusion. Finally, the administration of half-dose systemic thrombolytics also represents an option associated with a lower risk of bleeding, and no need for invasive procedures. Despite its low cost and promising initial outcomes, there are no studies with clinical endpoints to support its use. This strategy has also been used in patients with hemodynamic compromise, with promising outcomes. (4)

In conclusion, the group of patients with intermediate-high risk PTE is very heterogeneous, since there are patients who can benefit from each of the treatments mentioned above with thrombolytics as the main drug, as well as a group of patients who could benefit only from anticoagulation, or invasive procedures without thrombolytics, such as thrombectomy. Given this heterogeneity, the creation of Pulmonary Embolism Response Teams (PERT) is recommended for therapeutic decisions. (23) A recent analysis of the first PERT created in the world (Mass General Hospital, Massachusetts, United States) showed a significant increase in the use of reperfusion therapies in the PERT era, particularly of local thrombolytics in intermediate-risk patients, with no increased rate of bleeding. (24)

Ethical considerations

Not applicable.

Conflicts of interest

None declared.

(See authors' conflicts of interest forms on the website/ Supplementary material).

\section{REFERENCES}

1. Heit JA. The epidemiology of venous thromboembolism in the community: implications for prevention and management. J ThrombThrombolysis 2006;21:23-9. https://oi.org/10.1007/s11239006-5572-y

2. Ubaldini J, Chertcoff J, Sampó E, Casey M, Ceresetto J, Boughen R y cols. Consenso de Enfermedad Tromboembólica Aguda. Rev Argent Cardiol 2016;84:74-91.
3. Kearon C, Akl EA, Ornelas J, Blaivas A, Jiménez D, Bounameaux $\mathrm{H}$, et al. Antithrombotic Therapy for VTE Disease: CHEST Guideline and Expert Panel Report. Chest 2016;149:315-52. https://doi. org $/ 10.1016 / j$.chest.2015.11.026

4. Konstantinides SV, Meyer G, Becattini C, Bueno H, Geersing GJ, Harjola VP, et al. 2019 ESC Guidelines for the diagnosis and management of acute pulmonary embolism developed in collaboration with the European Respiratory Society (ERS). Eur Heart J 2020;41:543603. https://doi.org/10.1093/eurheartj/ehz405

5. Giri J, Sista AK, Weinberg I, Kearon C, Kumbhani DJ, Desai ND, et al. Interventional Therapies for Acute Pulmonary Embolism: Current Status and Principles for the Development of Novel Evidence: A Scientific Statement From the American Heart Association. Circulation 2019;140:e774-e801. https://doi.org/10.1161/ CIR.0000000000000707

6. Elias A, Mallett S, Daoud-Elias M, Poggi JN, Clarke M. Prognostic models in acute pulmonary embolism: a systematic review and meta-analysis. BMJ Open 2016;6:e010324. https://doi.org/10.1136/ bmjopen-2015-010324

7. Becattini C, Cimini LA, Vedovati MC. Patients with acute pulmonary embolism at intermediate risk for death: Can we further stratify? Eur J InternMed $2019 ; 65: 29-31$. https://doi.org/10.1016/j. ejim.2019.06.008

8. Cigalini IM, Igolnikof DB, Scatularo CE, Jáuregui JC, Bernal MI, Aboy JA y cols. Tromboembolismo pulmonar agudo en la Argentina. Registro CONAREC XX. Rev Argent Cardiol 2019;87:137-45.

9. Gagliardi JA, Charask A, Perna E, D'Imprio H, Bono J, Castillo Costa Y y cols. Rev Argent Cardiol 2016;84:548-57. https://doi. org/10.7775/rac.es.v84.i6.9508

10. Meyer G, Vicaut E, Danays T, Agnelli G, Becattini C, BeyerWestendorf J, et al. Fibrinolysis for patients with intermediate-risk pulmonary embolism. N Engl J Med 2014;370:1402-11. https://doi. org/10.1056/NEJMoa1302097

11. Barco S, Vicaut E, Klok FA, Lankeit M, Meyer G, Konstantinides SV; PEITHO Investigators. Improved identification of thrombolysis candidates amongst intermediate-risk pulmonary embolism patients: implications for future trials. Eur Respir J 2018;51:1701775. https://doi.org/10.1183/13993003.01775-2017

12. Ruiz-Giménez N, Suárez C, González R, Nieto JA, Todolí JA, Samperiz AL, Monreal M; RIETE Investigators. Predictive variables for major bleeding events in patients presenting with documented acute venous thromboembolism. Findings from the RIETE Registry. Thromb Haemost 2008 ; 100:26-31. https://doi.org/10.1160/TH08-03-0193

13. Chatterjee S, Chakraborty A, Weinberg I, Kadakia M, Wilensky RL, Sardar P, Kumbhani DJ, Mukherjee D, Jaff MR et al. Thrombolysis for pulmonary embolism and risk of all-cause mortality, major bleeding, and intracranial hemorrhage: a meta-analysis. JAMA 2014;311:2414-21. https://doi.org/10.1001/jama.2014.5990

14. Sharp ASP, Attallah A. Future perspectives in catheter-based treatment of pulmonary embolism. Eur Heart J Suppl 2019;21(Suppl I):I31-7. https://doi.org/10.1093/eurheartj/suz226

15. Schultz J, Andersen A, Kabrhel C, Nielsen-Kudsk JE. Catheterbased therapies in acute pulmonary embolism. EuroIntervention 2018;13:1721-7. https://doi.org/10.4244/EIJ-D-17-00437

16. Schmitz-Rode T, Kilbinger M, Günther RW. Simulated flow pattern in massive pulmonary embolism: significance for selective intrapulmonary thrombolysis. Cardiovasc Intervent Radiol 1998;21:199204. https://doi.org/10.1007/s002709900244

17. Tapson VF, Sterling K, Jones N, Elder M, Tripathy U, Brower $\mathrm{J}$ et al. A Randomized Trial of the Optimum Duration of Acoustic Pulse Thrombolysis Procedure in Acute Intermediate-Risk Pulmonary Embolism: The OPTALYSE PE Trial. JACC Cardiovasc Interv 2018;11:1401-10. https://doi.org/10.1016/j.jcin.2018.04.008

18. Kucher N, Boekstegers P, Müller OJ, Kupatt C, Beyer-Westendorf J, Heitzer T, et al. Randomized, controlled trial of ultrasoundassisted catheter-directed thrombolysis for acute intermediate-risk pulmonary embolism. Circulation 2014;129:479-86. https://doi. org/10.1161/CIRCULATIONAHA.113.005544

19. Kuo WT, Banerjee A, Kim PS, DeMarco FJ Jr, Levy JR, Facchini FR, et al. Pulmonary Embolism Response to Fragmentation, Embolectomy, and Catheter Thrombolysis (PERFECT): Initial Results From a Prospective Multicenter Registry. Chest 2015;148:667-73. https://doi.org/10.1378/chest.15-0119

20. Piazza G, Hohlfelder B, Jaff MR, Ouriel K, Engelhardt TC, Sterling KM. A Prospective, Single-Arm, Multicenter Trial of Ul- 
trasound-Facilitated, Catheter-Directed, Low-Dose Fibrinolysis for Acute Massive and Submassive Pulmonary Embolism: The SEATTLE II Study. JACC Cardiovasc Interv 2015;8:1382-92. https://doi. org/10.1016/j.jcin.2015.04.020

21. Engelberger RP, Stuck A, Spirk D, Willenberg T, Haine A, Périard D, et al. Ultrasound-assisted versus conventional catheterdirected thrombolysis for acute iliofemoral deep vein thrombosis: 1-year follow-up data of a randomized-controlled trial. J Thromb Haemost 2017;15:1351-60. https://doi.org/10.1111/jth.13709

22. Sharifi M, Bay C, Skrocki L, Rahimi F, Mehdipour M; "MOPETT" Investigators. Moderate pulmonary embolism treated with throm- bolysis (from the "MOPETT" Trial). Am J Cardiol 2013;111:273-7. https://doi.org/10.1016/j.amjcard.2012.09.027

23. Rosovsky R, Zhao K, Sista A, Rivera-Lebron B, Kabrhel C. Pulmonary embolism response teams: Purpose, evidence for efficacy, and future research directions. Res Pract Thromb Haemost 2019;3:315-30. https://doi.org/10.1002/rth2.12216

24. Rosovsky R, Chang Y, Rosenfield K, Channick R, Jaff MR, Weinberg I. Changes in treatment and outcomes after creation of a pulmonary embolism response team (PERT), a 10-year analysis. J Thromb Thrombolysis 2019 ;47:31-40.https://doi.org/10.1007/ s11239-018-1737-8

\section{Con}

IGNACIO MANUEL CIGALINI ID

Pulmonary thromboembolism is the third cause of cardiovascular death worldwide and the leading preventable cause of hospital death. (1-3) It is also a great diagnostic and therapeutic challenge due to its wide spectrum of clinical presentations and outcomes, comprising asymptomatic patients or with mild dyspnea to sudden death. (4) As a result, it is necessary to stratify the severity of the condition to guide its therapeutic management. In this regard, hemodynamically stable patients with preserved RV function and no evidence of myocardial injury are classified as low-risk patients and have an excellent short-term prognosis. Conversely, hemodynamically unstable patients have a high risk of mortality due to progressive RV dysfunction and shock, and are considered at high risk (or massive PTE), with an estimated in-hospital mortality $>15 \%$. Finally, hemodynamically stable patients with evidence of RV dysfunction or myocardial injury are defined as intermediate-risk (or submassive PTE) patients with an estimated mortality of 3-15\%. (5-7)

Rapid initiation of anticoagulation is the mainstay of treatment in all strata due to its proven effect in reducing early death and recurrence of symptomatic or fatal venous thromboembolic disease. (8) In turn, systemic thrombolytic agents have shown rapid thrombus dissolution and improvement of hemodynamic parameters compared with anticoagulation alone. (9, 10) However, their benefits might not be enough to compensate for the resulting increase in major bleeding complications, with a net benefit that would only be favorable in high-risk PTE patients. (5) While RV dysfunction and evidence of myocardial injury are associated with worse short-term prognosis in the absence of hypotension or shock, (11-13) the role of systemic thrombolysis in these patients remains highly controversial.

Historically, there has been much less research on the development of new technologies and therapeutic approaches to improve PTE morbidity and mortality rates compared to research on the management of acute myocardial infarction and stroke, resulting in a limited quality of available information. This situ- ation is evident since less than 1,000 patients were included in the first 40 years of studies on the impact of thrombolytic therapy for this condition. (14) Fortunately, in recent years there has been a renewed interest mainly in trying to answer this question.

In this regard, the PEITHO study was the most ambitious trial, powerful enough to evaluate the clinical efficacy and safety of systemic infusion of thrombolytics in 1,006 intermediate-risk PTE patients with acute PTE, evidence of RV dysfunction (by echocardiography or CT scan), and myocardial injury without arterial hypotension. (15)

Systemic infusion of weight-adjusted tenecteplase was compared with anticoagulation alone, considering as endpoint the composite of all-cause death or hemodynamic decompensation. Although a decrease in the primary endpoint was demonstrated at 7 days $(2.6 \%$ vs. $5.6 \% ; \mathrm{p}=0.02$ ), this was the result of a reduction in the development of hemodynamic decompensation ( $1.6 \%$ vs. $5 \% ; \mathrm{p}=0.002)$ with no impact on mortality at $7(1.2 \%$ vs. $1.8 \% ; \mathrm{p}=0.42)$ or 30 days $(2.4 \%$ vs. $3.2 \%$, $\mathrm{p}=0.42)$. In addition, there was a significant increase in major bleeding ( $11.5 \%$ vs. $2.4 \%$; p >0.001), and 12 times higher rate of stroke $(2.4 \%$ vs. $0.2 \% ; \mathrm{p}=0.003)$ at the expense of hemorrhagic stroke ( $2 \%$ vs. $0.2 \%$ ).

Long-term follow-up at 3 years also showed no difference in mortality $(20.3 \%$ vs. $18 \%$; p $=0.43)$, persistent symptoms or functional limitation (36\% vs. $30.1 \%, \mathrm{p}=0.23$ ). (16) Similarly, no difference was found in the incidence of chronic thromboembolic pulmonary hypertension in 290 patients with echocardiographic follow-up (2.1\% vs. $3.2 \%, \mathrm{p}=0.79)$.

Several meta-analyses have been carried out to increase the power and accuracy for estimating the effect of thrombolytic therapy in PTE. Marti et al. reported a reduction in all-cause mortality with the use of thrombolytics regardless of PTE severity (OR 0.59; 95\% CI, 0.36-0.96). (17) However, this difference is not significant when only studies of good methodological quality are analyzed (Jadad 4-5 scale), or when studies including high-risk patients are ruled out. This finding reinforced the consensus to indicate systemic re- 
perfusion only to patients with hemodynamic decompensation, becoming the basis of the recommendation in international guidelines. (5) A significant increase in major bleeding (OR 2.91; 95\% CI, 1.95-4.36) and more than triple increase in the composite endpoint of fatal or intracranial bleeding (OR 3.18; 95\% CI, 1.258.11) was also registered with the use of thrombolytics. Similar results were reported with a Cochrane systematic review and meta-analysis. (18)

Nakamura et al. evaluated 1,510 patients with intermediate PTE enrolled in 6 randomized studies and found no difference in the composite endpoint of all cause death or recurrent PTE ( $3.1 \%$ vs. $5.4 \%$; $=0.2$ ), although there was a reduction in the composite endpoint of death or clinical deterioration (3.9\% vs. $9.4 \%$, $\mathrm{p}=0.001$ ). (19) Chatterjee et al. performed a prespecified analysis to evaluate the impact of thrombolytics in 8 trials including patients with intermediate-risk PTE $(\mathrm{n}=1,775)$ and found lower mortality $(2.17 \% \mathrm{vs}$. $3.89 \%$, OR $0.48,95 \%$ CI, $0.25-0.92, \mathrm{p}=0.03$ ) with an increase in major bleeding events $(7.74 \%$ vs. $2.25 \%$. OR 3.19, 95\% CI, 2.07-4.92, p > 0.001). (20) However, this analysis included studies using unproven lowdoses of thrombolytic agents, (21) and even trials using associated endovascular techniques. (22) Precisely, the authors highlight the need to standardize thrombolytic doses and their (systemic or local) method of administration in order to maximize the benefits.

Several meta-analyses on intermediate-risk PTE patients have been published in recent years, demonstrating benefits in terms of efficacy, though at the expense of complications. (23-25) These studies have major limitations as a result of non-individualized analysis of trials with inconsistent definitions of submassive or intermediate PTE, which compare different thrombolytic and anticoagulant treatment protocols based on endpoints with heterogeneous definitions (Table 1).

When the main cause of death due to a condition is associated with RV dysfunction, (5) it is expected that the methods showing a rapid thrombus dissolution and subsequent afterload reduction will result in decreased PTE clinical events. Although there is a lower mortality trend in the above-mentioned studies, the results are not conclusive. Their main efficacy result is a significant reduction of hemodynamic deterioration and need for treatment scaling, often defined as the need for the use of thrombolytic agents. In other words, the systematic use of thrombolytic agents would reduce the need to use them in case of unfavorable course without a proven impact on mortality.

Furthermore, the significant increase in major, intracranial and fatal bleeding in the different studies analyzed is remarkable and homogeneous, even considering that patients with low bleeding risk were specially selected. $(17,18,20)$ As a result, it is necessary to develop alternative methods with a better safety profile.

The percutaneous approach to PTE has garnered interest as a result of the limitations in the use of systemic thrombolytics and the complexity and risk associated with open surgical embolectomy. $(26,27)$ Although rudimentary fragmentation/maceration techniques could have an impact on decompensated patients with proximal occlusion of the pulmonary branches, allowing restoration of flow and partial RV decompression until the additive effect of thrombolytic therapy is achieved, the embolic potential to the distal circulation might result in increased pulmonary resistance and RV afterload. (28) This limitation has led to the advent of specific devices, which can be divided into two groups:

- Catheter-directed thrombolysis associated (or not) with fragmentation, maceration or ultrasound (thrombolysis -assisted ultrasound, TAUS) techniques, which would enhance the lytic effect by promoting thrombus disintegration and by exposing an increased total surface area for its action. Low doses are administered directly to the affected segment of the pulmonary circulation to overcome the theoretical limitation of peripheral administration and its eventual deviation to unobstructed segments. (29)

- Aspiration, mechanical or rheolytic endovascular embolectomy devices that would offer immediate relief of pulmonary obstruction with no need for thrombolytics, (30) are particularly attractive when considering that lytics are contraindicated in one third of patients with hemodynamic decompensation. (31)

The available evidence for the use of endovascular therapies in PTE is based on small randomized, controlled trials, prospective uncontrolled trials and retrospective cohorts that assess the feasibility, surrogate endpoints of efficacy and safety of the different techniques. ULTIMA was the only randomized, controlled clinical trial that compared TAUS with anticoagulation alone, and demonstrated superiority in improving RV dysfunction in intermediate-risk PTE patients. (22) In turn, different studies demonstrated a rapid reversal of $\mathrm{RV}$ dysfunction, one of the most analyzed variables due to its independent association with poor prognosis. (32-38)

A meta-analysis of 2,135 patients undergoing TAUS showed a significant improvement in different clinical and hemodynamic parameters in patients with massive and submassive PTE, since 5.4\% major bleeding was observed compared with $11.5 \%$ reported in the PEITHO study. (39)

In addition, data from 566 patients enrolled in 6 prospective studies that used different endovascular techniques recorded a weighted average of $4.5 \%$ (95\% CI, $1.1 \%-7.5 \%)$ major non-intracranial bleeding and $0.7 \%$ (95\% CI, 0\%-1.3\%) intracranial bleeding. (26) In this regard, indirect comparisons suggest that endovascular techniques could be associated with about half major and intracranial bleeding complications resulting from the systemic use of thrombolytics. How- 
ever, it should be pointed out that no prospective trials comparing the two therapies have been published so far to further support this hypothesis.

An analysis evaluating 3,252 hemodynamically stable PTE patients with RV dysfunction showed no significant differences in mortality $(7.7 \%$ vs. $8.7 \%$, p $=0.51$ ) or hospital stay ( 8.8 vs. $9.57 \mathrm{~d}, \mathrm{p}=0.5)$, regardless of whether thrombolytics were used (13.13\%) or not. (40) On the other hand, the administration of lytics to hemodynamically unstable patients resulted in a significant reduction of in-hospital mortality (33\% vs. $18.1 \%, \mathrm{p}=0.0015$ ).

In turn, different registries including real-life patients report an incidence of bleeding $>20 \%$ and hemorrhagic stroke of $3 \%-5 \%,(41,42)$ much higher than those reported in clinical trials including specially selected populations.

Finally, data from the contemporary CONAREC XX registry, including 684 PTE patients from 75 centers in Argentina, demonstrated that reperfusion therapies were used in $16 \%$ of high-intermediate risk patients, and only $49 \%$ of patients with hemodynamic decompensation recorded $10.3 \%$ major bleeding complications. (43) The low use of reperfusion therapies in high-risk patients is similar to that reported in other registries, in which the reperfusion rate in decompensated patients is alarmingly lower. (44-46)
Before indicating thrombolysis to a segment of patients with dubious benefits, we should further analyze the need for administration in those patients with hemodynamic collapse, whose net benefit is clearly favorable. $(5,17,18,40)$

In conclusion, so far there is no quality evidence to support the use of systemic thrombolytics on a routine basis for patients with acute PTE, ventricular dysfunction, or myocardial injury without hemodynamic instability. However, the poor prognosis of these patients makes it necessary to further analyze clinical trials evaluating other therapeutic options. In that regard, endovascular therapies alone or in combination with low doses administered locally could be an option, since they have demonstrated comparable efficacy benefits with an apparently superior safety profile. For the moment, the indication of systemic pharmacological reperfusion should be adopted by assessing the potential risks and benefits of each particular case.

Ethical considerations

Not applicable.

Conflicts of interest

None declared.

(See authors' conflicts of interest forms on the website/ Supplementary material). 


\begin{tabular}{|c|c|c|c|c|c|c|}
\hline TABLE & & & & & & \\
\hline & $\begin{array}{l}\mathrm{N}^{\circ} \text { of } \\
\text { patients }\end{array}$ & $\begin{array}{l}\text { Intermediate/Submassive PTE } \\
\text { criteria }\end{array}$ & Lytic evaluation & AC used & Efficacy endpoints & Safety endpoints \\
\hline $\begin{array}{l}\text { Goldhaber et al., } \\
\text { (10) } 1993\end{array}$ & 36 & RV hypokinesis by TTE & $100 \mathrm{mg}$ TPA in $2 \mathrm{~h}$ & UFH & $\begin{array}{l}\text { PEP: Improvement in RV } \\
\text { dysfunction at } 24 \mathrm{~h} 89 \% \text { vs } \\
44 \% \text {; }(p=0.03)\end{array}$ & $\begin{array}{l}\text { Reported only for the } \\
\text { global cohort. }\end{array}$ \\
\hline $\begin{array}{l}\text { MAPPET-3, } \\
\text { (47) } 2002\end{array}$ & 256 & $\begin{array}{l}\text { RV dysfunction by TTE (RV en- } \\
\text { largement and lack of IVC inspi- } \\
\text { ratory collapse), PAH by TTE (tri- } \\
\text { cuspid regurgitant jet }>2.8 \mathrm{~m} / \mathrm{s} \text { ), } \\
\text { precapillary PAH in right catheter- } \\
\text { ization (mPAP }>20 \mathrm{mmHg} \text { with } \\
\text { Wedge }<18 \mathrm{mmHg} \text { ) or signs } \\
\text { of RV overload in ECG (IRBBB } \\
\text { or CRBBB, } \mathrm{S} \text { in DI and Q in DIII, } \\
\text { negative T-waves in V1-3), }\end{array}$ & $\begin{array}{l}10 \mathrm{mg} \text { bolus of TPA, } \\
\text { and } 90 \mathrm{mg} \text { in } 2 \mathrm{~h} \text {. }\end{array}$ & UFH & $\begin{array}{l}\text { PEP: In-hospital mortality or } \\
\text { clinical deterioration: } 11 \% \text { vs } \\
24.6 \% \text {; }(p=0.006) \\
\text { - In-hospital mortality } 3.4 \% \\
\text { vs } 2.2 \% \text {; }(p=0.71 \text { ) } \\
\text { - Clinical deterioration (cat- } \\
\text { echolamine infusion, OTI, } \\
\text { CPR, thrombolysis, surgical } \\
\text { embolectomy or catheter } \\
\text { fragmentation): } 10.2 \% \text { vs } \\
24.6 \% ;(p=0.004)\end{array}$ & $\begin{array}{l}\text { Major bleeding (fatal, in- } \\
\text { tracranial or drop of } 4 \mathrm{~g} / \\
\mathrm{dL} \text { Hb): } 0.8 \% \text { vs } 3.6 \% \text {; }(\mathrm{p} \\
=0.29 \text { ) }\end{array}$ \\
\hline $\begin{array}{l}\text { Lu et al. } \\
\text { (48) } 2008\end{array}$ & 106 & RV dysfunction by TTE & $\begin{array}{l}20000 \mathrm{IU} / \mathrm{kg} \text { bolus of } \\
\text { urokinase }\end{array}$ & LMWH & $\begin{array}{l}\text { PEP: Death or TPE recurrence } \\
\text { at } 1 \text { year: } 13.7 \% \text { vs } 14.5 \% \text {; } \\
(p=n s)\end{array}$ & Bleeding: $1.9 \%$ vs $0 \%$ \\
\hline $\begin{array}{l}\text { TIPES (49), } \\
2010\end{array}$ & 58 & $\begin{array}{l}\text { RV dysfunction by TTE (RV-LV } \\
\text { end diastolic diameter }>\text { in apical } \\
\text { four-chamber view, or }>0.7 \text { in } \\
\text { parasternal long axis view). }\end{array}$ & $\begin{array}{l}\text { 30-50 } \mathrm{mg} \text { bolus of } \\
\text { TNK adjusted by } \\
\text { weight }\end{array}$ & UFH & $\begin{array}{l}\text { PEP: Reduction of RV-LV rela- } \\
\text { tion at } 24 \mathrm{~h}: 0.31 \pm 0.08 \text { vs. } \\
0.1 \pm 0.07 \text { ( } p=0.04 \text { ). } \\
\text { - Clinical deterioration; treat- } \\
\text { ment scaling needed at } \\
7 \mathrm{~d} \text {. or discharge: } 0 \% \text { vs } \\
3.3 \% \text {; ( } p=n s) \\
\text { - TPE recurrence: } 3.6 \% \text { vs } \\
3.3 \% \text {; }(p=n s)\end{array}$ & $\begin{array}{l}\text { Major bleeding (fatal, in- } \\
\text { tracranial, need for trans- } \\
\text { fusion or intervention due } \\
\text { to hemodynamic decom- } \\
\text { pensation) within } 7 \text { days } \\
\text { or at discharge: } 7.1 \% \text { vs } \\
3.3 \% \text {; }(p=n s \text { ) }\end{array}$ \\
\hline $\begin{array}{l}\text { Fasullo et al., } \\
\text { (50) } 2011\end{array}$ & 72 & $\begin{array}{l}\text { RV dysfunction by TTE (McCon- } \\
\text { nell's sign, paradoxical septal } \\
\text { motion, new TR, RV enlargement } \\
>30 \mathrm{~mm} \text {, RV-LV end diastolic di- } \\
\text { ameter }>1 \text { in apical four-chamber } \\
\text { view, or >0.7 in parasternal } \\
\text { long axis view, PAH, IVC dilation } \\
\text { without inspiratory collapse, right } \\
\text { pulmonary artery dilation }>12 \\
\mathrm{~mm} / \mathrm{m} 2 \text { ) }\end{array}$ & $\begin{array}{l}10 \mathrm{mg} \text { bolus of TPA, } \\
\text { and } 90 \mathrm{mg} \text { in } 2 \mathrm{~h} \text {. }\end{array}$ & UFH & $\begin{array}{l}\text { PEP Reduction of RV dysfunc- } \\
\text { tion by TIE: improvement of } \\
\text { the different parameters. } \\
\text { - In-hospital mortality } 0 \% \text { vs } \\
14.2 \% ;(p=0.055)\end{array}$ & $\begin{array}{l}\text { In-hospital major bleeding } \\
\text { (fatal, intracranial, need } \\
\text { for transfusion or inter- } \\
\text { vention due to hemody- } \\
\text { namic decompensation): } \\
5.4 \% \text { vs } 2.9 \% \text {; }(p=n s \text { ) }\end{array}$ \\
\hline $\begin{array}{l}\text { MOPETT, } \\
\text { (21) } 2012\end{array}$ & 121 & $\begin{array}{l}\text { Thrombotic involvement }>70 \% \\
\text { in } \geq 2 \text { lobar segments or in left or } \\
\text { right main branches by CT scan } \\
\text { or mismatch in } \geq 2 \text { lobar seg- } \\
\text { ments in high-probability ventila- } \\
\text { tion-perfusion scintigraphy. }\end{array}$ & $\begin{array}{l}10 \mathrm{mg} \text { bolus of TPA, } \\
\text { and } 40 \mathrm{mg} \text { in } 2 \mathrm{~h}(0.5 \\
\mathrm{mg} / \mathrm{kg} \text { in }<50 \mathrm{~kg})\end{array}$ & $\begin{array}{l}\text { IV UFH } \\
\text { or SC } \\
\text { LMWH } \\
( \pm 80 \%)\end{array}$ & $\begin{array}{l}\text { PEP: development of PAH by } \\
\text { TIE (PASP } \geq 40 \mathrm{mmHg} \text { ) at } \\
28 \pm 5 \text { d: } 16 \% \text { vs } 57 \% \text {; ( } p \\
=0.001 \text { ) } \\
\text { - Development of PAH by } \\
\text { TE or recurrent PTE: } 16 \% \\
\text { vs } 63 \% ;(p=0.001) \\
\text { - Mortality: } 1.6 \% \text { vs } 5 \% \text {; ( } p \\
=0.3) \\
\text { - PTE recurrence: } 0 \% \text { vs } 5 \% \text {; } \\
(p=0.08)\end{array}$ & $\begin{array}{l}\text { In-hospital bleeding: } 0 \% \\
\text { vs } 0 \%\end{array}$ \\
\hline
\end{tabular}


(continue)

\begin{tabular}{|c|c|c|c|c|c|c|}
\hline & $\begin{array}{l}\mathrm{N}^{\circ} \text { of } \\
\text { patients }\end{array}$ & $\begin{array}{l}\text { Intermediate/Submassive PTE } \\
\text { criteria }\end{array}$ & Lytic evaluation & $A C$ used & Efficacy endpoints & Safety endpoints \\
\hline $\begin{array}{l}\text { TOPCOAT, } \\
\text { (51) } 2014\end{array}$ & 83 & $\begin{array}{l}\text { RV involvement by TTE (hypoki- } \\
\text { nesis), increased troponin I or T (> } \\
\text { percentile } 99 \% \text { ), BNP (> } 90 \mathrm{pg} / \\
\mathrm{mL} \text { ) or NTproBNP (>900 pg/mL). }\end{array}$ & $\begin{array}{l}30-50 \mathrm{mg} \text { bolus of } \\
\text { TNK adjusted by } \\
\text { weight }\end{array}$ & LMWH & $\begin{array}{l}\text { PEP: Death, hypotension; va- } \\
\text { sopressors or OTI required at } \\
5 \mathrm{~d}: 2.5 \% \text { vs } 7 \% \text {. } \\
\text { - PEP components, PTE re- } \\
\text { currence, poor functional } \\
\text { capacity or SF-36 health } \\
\text { questionnaire score < } 30 \\
\text { to } 90 \mathrm{~d}: 15 \% \text { vs } 37 \% \text {; ( } p \\
=0.017 \text { ) }\end{array}$ & $\begin{array}{l}\text { Fatal bleeding: } 2.5 \% \text { vs } \\
0 \% \\
\text { Hemorrhagic stroke: } \\
2.5 \% \text { vs } 0 \%\end{array}$ \\
\hline $\begin{array}{l}\text { PEITHO, } \\
\text { (15) } 2014\end{array}$ & 1,005 & $\begin{array}{l}\text { RV dysfunction by TTE (RV en- } \\
\text { largement }>30 \mathrm{~mm}, \mathrm{RV}-\mathrm{LV} \text { end } \\
\text { diastolic diameter }>0.9 \text { in apical } \\
\text { or subcostal four-chamber view, } \\
\text { RV free-wall hypokinesis or TR } \\
\text { peak velocity }>2.6 \mathrm{~m} / \mathrm{s} \text { in apical } \\
\text { or subcostal four-chamber view), } \\
\text { or CT (RV-LV index }>0.9 \text { ) and } \\
\text { myocardial injury (Troponin I > } \\
0.06 \text { ug/L or } T>0.01 \mathrm{ug} / \mathrm{L} \text { ). }\end{array}$ & $\begin{array}{l}30-50 \mathrm{mg} \text { bolus of } \\
\text { TNK adjusted by } \\
\text { weight }\end{array}$ & UFH & $\begin{array}{l}\text { PEP: All-cause mortality or } \\
\text { hemodynamic decompensa- } \\
\text { tion at } 7 \mathrm{~d}: 2.6 \% \text { vs } 5.6 \% \text {; } \\
(p=0.02) \\
\text { - Death: } 1.2 \% \text { vs } 1.8 \% \text {; ( } p \\
=0.42) \\
\text { - Hemodynamic decompen- } \\
\text { sation: } 1.6 \% \text { vs } 5 \% \text {; }(p= \\
0.002)\end{array}$ & $\begin{array}{l}\text { Major bleeding (fatal, in- } \\
\text { tracranial or drop of } 2 \mathrm{~g} / \\
\mathrm{dL} \mathrm{Hb} \text {, or need for } 2 \mathrm{RB}- \\
\text { CUs): } 11.5 \% \text { vs } 2.4 \% \text {; ( } p \\
=0.001 \text { ). Stroke: } 2.4 \% \\
\text { vs } 0.2 \% \text {; ( } p=0.003 \text { ). } \\
\text { Hemorrhagic stroke: } 2 \% \\
\text { vs } 0.2 \%\end{array}$ \\
\hline $\begin{array}{l}\text { Taherkhani et al., } \\
\text { (52) } 2014\end{array}$ & 50 & $\begin{array}{l}\text { RV dysfunction / enlargement } \\
\text { by TTE, with no LV impairment } \\
\text { or mitral valve disease or PAH by } \\
\text { TTE (TR peak velocity }>2.8 \mathrm{~m} / \mathrm{s} \text { ) }\end{array}$ & $\begin{array}{l}100 \mathrm{mg} \mathrm{TPA} \text { in } 90 \\
\text { min, or } 1500000 \mathrm{IU} \\
\text { of STK in } 2 \mathrm{~h} \text {. }\end{array}$ & LMWH & $\begin{array}{l}\text { PEP: in-hospital death or } \\
\text { clinical deterioration; treat- } \\
\text { ment scaling is required (cat- } \\
\text { echolamine infusion, rescue } \\
\text { thrombolytic therapy, OTI, } \\
\text { CPR, surgical embolectomy } \\
\text { or emergency catheter frag- } \\
\text { mentation): } 0 \% \text { vs } 24 \% \text {; ( } \\
=0.022 \text { ) }\end{array}$ & $\begin{array}{l}\text { Major bleeding (fatal, } \\
\text { hemorrhagic stroke, or } \\
\text { drop of } 4 \mathrm{~g} / \mathrm{dL} \mathrm{Hb} \text { ): } 0 \% \\
\text { vs } 0 \%\end{array}$ \\
\hline $\begin{array}{l}\text { ULTIMA, } \\
\text { (22) } 2014\end{array}$ & 59 & $\begin{array}{l}\text { Involvement of at least one ma- } \\
\text { jor branch or inferior lobar artery } \\
\text { and RV-LV diameter } \geq 1\end{array}$ & $\begin{array}{l}\text { TAUS with } 10-20 \mathrm{mg} \\
\text { local TPA in } 15 \mathrm{~h}\end{array}$ & UFH & $\begin{array}{l}\text { PEP: RV-LV reduction } 0.3 \\
\pm 0.2 \text { vs. } 0.03 \pm 0.16 \text { ( } p< \\
0.001 \text { ) at } 24 \mathrm{~h} \text {. } \\
\text { - Death at } 90 \mathrm{~d}: 0 \% \text { vs } 3.4 \% \\
\text { - Hemodynamic decompen- } \\
\text { sation at } 90 \mathrm{~d} 0 \% \text { vs. } 0 \% \\
\text { - Recurrent VTD at } 90 \mathrm{~d}: 0 \% \\
\text { vs } 0 \%\end{array}$ & $\begin{array}{l}\text { Major bleeding (drop of } 2 \\
\mathrm{~g} / \mathrm{dL} \mathrm{Hb} \text {, transfusion of } 2 \\
\text { RBCUs or critical site): } 0 \% \\
\text { vs } 0 \% \\
\text { Minor bleeding: } 10 \% \text { vs } \\
3 \%\end{array}$ \\
\hline $\begin{array}{l}\text { Sinha et al., } \\
\text { (53) } 2017\end{array}$ & 86 & $\begin{array}{l}\text { RV dysfunction (RV-LV diameter }> \\
0.9 \text {, or TAPSE }<16 \mathrm{~mm} \text { ) by TTE or } \\
\text { myocardial lesion. }\end{array}$ & $\begin{array}{l}\text { TNK bolus adjusted by } \\
\text { weight. }\end{array}$ & UFH & $\begin{array}{l}\text { PEP: Death or hemodynamic } \\
\text { decompensation at } 7 d 4.5 \% \\
\text { vs. } 20 \% \text {; }(p=0.04) \\
\text { - Death: } 4.5 \% \text { vs } 5 \% \text {; }(p= \\
\text { 0.3) } \\
\text { - Hemodynamic decompen- } \\
\text { sation: } 4.5 \% \text { vs } 20 \% \text {; ( } p \\
=0.04) \\
\text { - TPE recurrence: } 4.5 \% \text { vs } \\
2 \%(p=0.3)\end{array}$ & $\begin{array}{l}\text { Hemorrhagic stroke at } 7 \\
\mathrm{~d}: 2 \% \text { vs } 0 \% \text {; ( } p=n s \text { ) } \\
\text { Major bleeding (fatal, in } \\
\text { critical site, drop of } 2 \mathrm{~g} / \mathrm{dL} \\
\mathrm{Hb} \text {, or need for } 2 \text { RBCUs) } \\
\text { at } 7 \mathrm{~d} \text { : } 2 \% \text { vs } 2 \% \text {; }(p=n s \text { ) } \\
\text { Minor bleeding: } 16 \% \text { vs } \\
12 \% ;(p=0.04)\end{array}$ \\
\hline $\begin{array}{l}\text { Ahmeda et al., } \\
\text { (54) } 2018\end{array}$ & 52 & $\begin{array}{l}\text { RV dysfunction by TTE (McCon- } \\
\text { nell's sign, RV enlargement > } \\
30 \mathrm{~mm} \text { or RV-LV end diastolic } \\
\text { diameter }>1 \text {, TAPSE }<1.8 \mathrm{~cm} \text { or } \\
\text { PASP }>37 \mathrm{mmHg} \text { ) with elevated } \\
\text { biomarkers. }\end{array}$ & $\begin{array}{l}1,500,000 \mathrm{IU} \text { of STK } \\
\text { in } 2 \mathrm{~h}\end{array}$ & $\begin{array}{l}\text { Initial UFH, } \\
\text { followed by } \\
\text { LMWH }\end{array}$ & $\begin{array}{l}\text { PEP: PAH by TTE in } 72 \text { h } 50 \% \\
\text { vs } 78.6 \% ;(p=0.003)\end{array}$ & Bleeding: $0 \%$ vs $0 \%$ \\
\hline
\end{tabular}


Randomized clinical trials assessing the use of systemic thrombolytics in patients with submassive/ intermediate PTE compared with the use of anticoagulants alone. The ULTIMA trial is also included, the only study that compared ultrasound-assisted thrombolysis (TAUS) with anticoagulation alone. In all the cases, the initial outcome represents the study group (thrombolytic infusion) compared with the control group (anticoagulation alone).

AC: Anticoagulant. CPR: Cardiopulmonary resuscitation. CRBBB: Complete right bundle branch block. CT: Computed tomography. Hb: Hemoglobin. IRBBB: Incomplete right bundle branch block. IV: Intravenous. IVC: Inferior vena cava. LMWH: Low-molecular weight heparin. LV: Left ventricular. mPAP: Mean pulmonary artery pressure. OTI: Orotracheal intubation. PAH: Pulmonary artery hypertension. PASP: Pulmonary artery systolic pressure. PEP: Primary endpoint. PTE: Pulmonary thromboembolism. RBCU: Red blood cell unit. RV: Right ventricular. SC: Subcutaneous. STK: Streptokinase. TAPSE: Tricuspid annular plane systolic excursion. TNK: Tenecteplase. TPA: Alteplase. TR: Tricuspid regurgitation. TTE: Transthoracic echocardiography. UFH: Unfractionated heparin. VTD: Venous thromboembolic disease.

\section{REFERENCES}

1. Heit J. The epidemiology of venous thromboembolism in the community. Arterioscler Thromb Vasc Biol 2008;28:370-2. https://doi. org/10.1161/ATVBAHA.108.162545

2. Goldhaber S, Elliott C. Acute pulmonary embolism: part I: epidemiology, pathophisology, and diagnosis. Circulation 2003;108:27269. https://doi.org/10.1161/01.CIR.0000097829.89204.0C

3. Raskob G, An gchaisuksiri P, Blanco A, Buller H, Gallus A, Hunt B, et al. Thrombosis: a major contributor to global disease burden. Arterioescler Thromb Vasc Biol 2014;34:2363-71. https://doi. org/10.1161/ATVBAHA.114.304488

4. Cohen A, Agnelli G, Anderson F, Arcelus J, Bergqvist D, Brecht $\mathrm{J}$, et al. Venous thromboembolism (VTE) in Europe. The number of VTE events and associated morbidity and mortality. Thromb Haemost 2007; 98:756-64. https://doi.org/10.1160/TH07-03-0212

5.Kostantinides S, Meyer G, Becattini C, Bueno H, Geersing G, Harjola V, et al. 2019 ESC Guidelines for the diagnosis and management of acute pulmonary embolism developed in collaboration with the European Respiratory Society. Eur Heart J 2020;4: 543-603. https:// doi.org/10.1093/eurheartj/ehz405

6. Jaff M, McMurty S, Archer S, Cushman M, Goldenberg N, Goldhaber S, et al. Management of Massive and Submassive Pulmonary Embolism, Iliofemoral Deep Vein Thrombosis, and Chronic Thromboembolic Pulmonary Hypertension: A Scientific Statement From the American Heart Association. Circulation 2011;123: 1788-830. https://doi.org/10.1161/CIR.0b013e318214914f

7. Ubaldini J, Bilbao J, Spennato M, Bonorino J, Flores L, Kenar M, et al. Consenso de enfermedad tromboembólica aguda. Rev Argent Cardiol 2016; 84: 74-91.

8. Barrit D, SC J. Anticoagulant drugs in the treatment of pulmonary embolism. The Lancet 1960; 275: 1309-12. https://doi.org/10.1016/ S0140-6736(60)92299-6

9. Dalla-Volta S, Palla A, Santolicandro A, Giuntini C, Pengo C, Visioli $\mathrm{O}$, et al. PAIMS 2: alteplase combined with heparin versus heparin in the treatment of acute pulmonary embolism. Plasminogen activator Italian multicenter study 2. J Am Coll Cardiol 1992;20:520-6. https://doi.org/10.1016/0735-1097(92)90002-5

10. Goldhaber S, Haire W, Feldstein M, Miller M, Toltzis R, Smith J, et al. Alteplase versus heparin in acute pulmonary embolism: ran- domised trial assessing right-ventricular function and pulmonary perfusion. Lancet 1993;341:507-11. https://doi.org/10.1016/01406736(93)90274-K

11. Grifoni S, Olivotto I, Cecchini P, Pieralli F, Camaiti A, Santorio $\mathrm{G}$, et al. Short-term clinical outcome of patients with acute pulmonary embolism, normal blood pressure and echocardiographic right ventricular dysfunction. Circulation 2000;101:2817-22. https://doi. org/10.1161/01.CIR.101.24.2817

12.Kucher N, Rossi E, De Rosa M, Goldhaber S. Prognostic role of echocardiography among patients with acute pulmonary embolism and a systolic arterial pressure of $90 \mathrm{mmHg}$ or higher. Arch Intern Med 2005;165:1777-81. https://doi.org/10.1001/archinte.165.15.1777 13. Becattini C, Casazza F, Forgione C, Porro F, Fadin B, Stucchi A, et al. Acute Pulmonary Embolism: External Validation of an Integrated Risk Stratification Model. Chest 2013;144: 1539-45. https:// doi.org/10.1378/chest.12-2938

14. Wan S, Quinlan D, Agnelli G, Eikelboom J. Thrombolysis compared with heparin for the initial treatment of pulmonary embolism: a meta-analysis of the randomized controlled trials. Circulation 2004;110:744-9. https://doi.org/10.1161/01. CIR.0000137826.09715.9C

15. Meyer G, Vicaut E, Danays T, Agnelli G, Becattini C, BeyerWestendorf J, et al. Fibrinolysis for Patients with Intermediate-Risk Pulmmonary Embolism. N Engl J Med 2014;370:1402-11. https:// doi.org/10.1056/NEJMoa1302097

16. Konstantinides S, Vicaut E, Danays T, Becattini C, Bertoletti L, Beyer-Westendorf J, et al. Impact of thrombolytic therapy on the long-term outcome of intermediate-risk pulmonary embolism. J Am Coll Cardiol 2017; 69:1536-44. https://doi.org/10.1016/j. jacc.2016.12.039

17. Marti C, John G, Kostantinides S, Combescure C, Sanchez O, Lenkeit M, et al. Systemic thrombolytic therapy for acute pulmonary embolism: a systematic review and meta-analysis. Eur Heart J 2014; 36:605614. https://doi.org/10.1093/eurheartj/ehu218

18.Hao Q, Dong B, Yue J, T W, Liu G. Thrombolytic therapy for pulmonary embolism. Cochrane Database of Systematic Reviews 2018;12:CD004437. https://doi.org/10.1002/14651858.CD004437. pub5

19. Nakamura S, Takano H, Kubota Y, Asai K, Shimzu W. Impact of the efficacy of thrombolytic therapy on themortality of patients with acute submassive pulmonary embolism: a meta-analysis. J Thromb Haemost 2014; 12:1086-95. https://doi.org/10.1111/jth.12608

20. Chatterjee S, Chakrabort A, Weinberg I, Kadalka M, Wilensky R, Sardar P, et al. Thrombolysis for Pulmonary Embolism and Risk of All-Cause Mortality Major Bleeding and Intracranial Hemorrhage. A Meta-Analysis. JAMA 2014;311:2414-21. https://doi.org/10.1001/ jama.2014.5990

21. Sharifi M, Bay C, Skrocki L, Rahimi F, Mehdipour M. Moderate pulmonary embolism treated with thrombolysis (from the "MOPETT" Trial). Am J Cardiol 2013;111:273-7. https://doi. org/10.1016/j.amjcard.2012.09.027

22. Kucher N, Boekstegers P, Muller O, Kupatt C, Beyer-Westendorf J, Heitzer T, et al. Randomized controlled trial of ultrasoundassisted catheter directed thrombolyis for acute intermediate-risk pulmonary embolism. Circulation 2014; 129: 479-86. https://doi. org/10.1161/CIRCULATIONAHA.113.005544

23. Chen H, Ren C, Chen H. Thrombolysis Versus Anticoagulation for the Initial Treatment of Moderate Pulmonary Embolism: A Meta-Analysis of Randomized Controlled Trials. Respir Care 2014;59:1880-7. https://doi.org/10.4187/respcare.03197

24. Gao G, Yang P, Liu M, Ding M, Liu G, Tong Y, et al. Thrombolysis for acute intermediate-risk pulmonary embolism: A metaanalysis. Thromb Res 2015;136:932-7. https://doi.org/10.1016/j. thromres.2015.09.012

25. Izcovich A, Criniti J, Popoff F, Lu L, Wu J, Ageno W, et al. Thrombolytics for venous thromboembolic events: a systematic review with meta-analysis. Blood Adv 2020;4:1539-53. https://doi.org/10.1182/ bloodadvances. 2020001513

26. Giri J, Sista A, Weinberg I, Kearon C, Kumbhani D, Desai N, et al. Interventional Therapies for Acute Pulmonary Embolism: Current Status and Principles for the Development of Novel Evidence. A Scientific Statement From the American Heart Association. Circulation 2019;140:e774-e801. https://doi.org/10.1161/CIR.0000000000000707 27. de Winter M, Vlachojannis G, Ruigrok D, Nijkeuter M, Kraai- 
jeveld A. Rationale for catheter-based therapies in acute pulmonary embolism. Eur Heart J 2019; 21:I16-I22. https://doi.org/10.1093/eurheartj/suz223

28. Nakazawa K, Tajima H, Murata S, Kumita S, Yamamoto T, Tanaka K. Catheter fragmentation of acute massive pulmonary thromboembolism: distal embolisation and pulmonary arterial pressure elevation. Br J Radiol 2008; 81:848-54. https://doi.org/10.1259/ bjr/93840362

29. Schmitz-Rode T, Kilbinger M, Günther R. Simulated flow pattern in massive pulmonary embolism: significance for selective intrapulmonary thrombolysis. Cardiovasc Intervent Radiol 1998;21:199-204. https://doi.org/10.1007/s002709900244

30. Jaber W, McDaniel M. Catheter-Based Embolectomy for Acute Pulmonary Embolism. Devices, Technical Considerations, Risks and Benefits. Interv Cardiol Clin 2018; 7: 91-101. https://doi. org/10.1016/j.iccl.2017.08.003

31. Stein P, Matta F. Thrombolytic Therapy in Unstable Patients with Acute Pulmonary Embolism: Saves Lives but Underused. Am J Med 2012;125: 465-70. https://doi.org/10.1016/j.amjmed.2011.10.015 32. Piazza G, Hohlfelder B, Jaff M, Ouriel K, Engelhardt T, Sterling $\mathrm{K}$, et al. A prospective, single-arm, multicenter trial of ultrasoundfacilitated, catheter-directed, low-dose fibrinolysis for acute massive and submassive pulmonary embolism: the SEATTLE II study. JACC Cardiovasc Interv 2015; 8:1382-92. https://doi.org/10.1016/j. jcin.2015.04.020

33. Tapson V, Sterling K, Jones N, Elder M, Tripathy U, Brower J, et al. A Randomized Trial of the Optimum Duration of Acoustic Pulse Thrombolysis Procedure in Acute Intermediate-Risk Pulmonary Embolism: the OPTALYSE PE trial. JACC Cardiovasc Interv 2018;11:1401-10. https://doi.org/10.1016/j.jcin.2018.04.008

34. Kuo W, Banerjee A, Kim P, DeMarco FJ, Levy J, Facchini F, et al. Pulmonary Embolism Response to Fragmentation, Embolectomy, and Catheter Thrombolysis (PERFECT): initial results froma a prospective multicenter registry. Chest 2015;148:667-73. https://doi. org/10.1378/chest.15-0119

35. Ozcinar E, Cakici M, Dikmen Yaman N, Bran C, Aliyev A, Inan $\mathrm{B}$, et al. Thrombus resolution and right ventricular functional recovery using ultrasound-accelerated thrombolysis in acute massive and submassive pulmonary embolism. Int Angiol 2017;36: 428-37.

36. Bloomer T, El-Hayek G, McDaniel M, Sanvall B, Liberman H, Devireddy C, et al. Safety of catheter-directed thrombolysis for massive and submassive pulmonary embolism: Results of a multicenter registry and meta-analysis. Catheter Cardiovasc Interv 2017; 89:75460. https://doi.org/10.1002/ccd.26900

37. Hennemeyer C, Khan A, McGregor H, Moffett C, Woodhead G. Outcomes of Catheter-Directed Therapy Plus Anticoagulation Versus Anticoagulation Alone for Submassive and Massive Pulmonary Embolism. Am J Med 2019;132: 240-6. https://doi.org/10.1016/j.amjmed.2018.10.015

38. Tu T, Toma C, Tapson V, Adams C, Jaber W, Silver M, et al. A Prospective, Single-Arm, Multicenter Trial of Catheter-Directed Mechanical Thrombectomy for Intermediate-Risk Acute Pulmonary Embolism. The FLARE Study. JACC Cardiovasc Interv 2019; 12: 859-69. https://doi.org/10.1016/j.jcin.2018.12.022

39. Pei D, Liu J, Yaqoob M, Ahmad W, Bandeali S, Hamzeh I, et al. Meta-Analysis of Catheter Directed UltrasoundAssisted Thrombolysis in Pulmonary Embolism. Am J Cardiol 2019;124: 1470-7. https:// doi.org/10.1016/j.amjcard.2019.07.040

40. Desai H, Natt B, Bime C, Dill J, Dalen J, Alpert J. Pulmonary Embolism with Right Ventricular Dysfunction: Who Should Receive
Thrombolytic Agents? Am J Med 2017;130:. 93.e29-93.e32. https:// doi.org/10.1016/j.amjmed.2016.07.023

41.Konstantinides S, Geibel A, Olschewski M, Heinrich F, Grosser K, Rauber K, et al. Association Between Thrombolytic Treatment and the Prognosis of Hemodynamically Stable Patients With Major Pulmonary Embolism. Circulation 1997;96:882-8. https://doi. org/10.1161/01.CIR.96.3.882

42. Fiumara K, Kucher N, Fanikos J, Goldhaber S. Predictors of major hemorrhage following fibrinolysis for acute pulmonary embolism. Am J Cardiol 2006;97:127-19. https://doi.org/10.1016/j.amjcard.2005.07.117

43. Cigalini I, Igolnikof D, Scatularo C, Jáuregui J, Bernal M, Aboy J, et al. Tromboembolismo pulmonar agudo en la Argentina. Registro CONAREC XX. Rev Argent Cardiol. 2019;87:137-45.

44. Adusummalli S, Geller B, Yang L, Giri J, Groeneveld P. Trends in catheter directed thrombolysis and systemic thrombolysis for the treatment of pulmonry embolism. Am Heart J 2018;207:83-5. https://doi.org/10.1016/j.ahj.2018.09.013

45. Zuin M, Rigatelli G, Zuliani G, Zonzin P, Ramesh D, Roncon L. Thrombolysis in hemodynamically unstable patients: still underused: a review based on multicenter prospective registries on acute pulmonary embolism. J Thromb Thrombolysis 2019;48:323-30. https://doi.org/10.1007/s11239-019-01867-0

46. Keller K, Hobohm L, Ebner M, Kresoja K, Münzel T, Kostantinides S, et al. Trends in thrombolytic treatment and outcomes of acute pulmonary embolism in Germany. Eur Heart J. 2020;41:522-9. https://doi.org/10.1093/eurheartj/ehz236

47. Konstantinides S, Geibel A, Heusel G, Heinrich F, Kasper W. Heparin plus alteplase compared with heparin alone in patients with submassive pulmonary embolism. N Engl J Med 2002;347:1143-50. https://doi.org/10.1056/NEJMoa021274

48. Lu W, Tang Z, Ma Y, Yu Z. Long term prognosis of thrombolytic therapy with urokinase and/or anticoagulant in submassive pulmonary embolism. Clin J Med Offic 2008;36:340-2.

49. Becattini C, Agnelli G, Salvi A, Grifoni S, Pancaldi L, Enea I, et al. Bolus tenecteplase for right ventricle dysfunction in hemodynamically stable patients with pulmonary embolism. Thromb Res 2010;125:82-6. https://doi.org/10.1016/j.thromres.2009.09.017 50. Fasullo S, Scalzo S, Maringhini G, Ganci F, Cannizzaro S, Basile I, et al. Six-month echocardiographic study in patients with submassive pulmonary embolism and right ventricle dysfunction: comparison of thrombolysis with heparin. Am J Med Sci. 2011;341:33-9. https://doi.org/10.1097/MAJ.0b013e3181f1fc3e

51. Kline J, Nordenholz K, Courtney D, Kabrhel C, Jones A, Rondina M, et al. Treatment of submassive pulmonary embolism with tenecteplase or placebo: cardiopulmonary outcomes at 3 months: multicenter double-blind, placebo-controlled randomized trial. $\mathrm{J}$ Thromb Haemost. 2014;12:459-68. https://doi.org/10.1111/jth.12521 52.Taherkhani M, Taherkhani A, Hashemi S, Langroodi T, Sadeghi R, Beyranvand M. Thrombolytic-plus-Anticoagulant Therapy versus Anticoagulant-Alone Therapy in Submassive Pulmonary Thromboembolism (TVASPE Study): A Randomized Clinical Trial. J Tehran Heart Cent 2014; 9:104-8.

53. Sinha S, Sachan M, Goel A, Singh K, Mishra V, Jha M, et al. Efficacy and Safety of Thrombolytic Therapy in Acute Submassive Pulmonary Embolism: Follow-Up Study. J Clin Med Res 2017;9:1639. https://doi.org/10.14740/jocmr2829w

54. Ahmed M, Abdelsalam S, Elmorsy R. Value of thrombolytic therapy for submassive pulmonary embolism patients. Egypt J Chest Dis Tuberc 2018;67:413-8. 